\title{
PELATIHAN PEMBENAHAN PEMBUKUAN PADA USAHA ROTI IDOLA BUKITTINGGI
}

\author{
Ermatati Hatta ${ }^{1}$, Dita Maretha Rissi ${ }^{2}$, Ulfi Maryati ${ }^{3}$, \\ Rasyidah Mustika ${ }^{4}$, Welsi Haslina ${ }^{5}$ \\ ${ }^{1}$ Jurusan Akuntansi Politeknik Negeri Padang \\ Email: ermatati.hatta@gmail.com \\ 2Jurusan Akuntansi Politeknik Negeri Padang \\ Email: ditamaretharissi@gmail.com \\ ${ }^{3}$ Jurusan Akuntansi Politeknik Negeri Padang \\ Email: ulfimaryati@gmail.com \\ ${ }^{4} J u r u s a n$ Akuntansi Politeknik Negeri Padang \\ Email: titik.mustika@gmail.com \\ 5Jurusan Akuntansi Politeknik Negeri Padang \\ Email: welsih@yahoo.com
}

\begin{abstract}
Micro, Small and Medium Enterprises (MSMEs) have a role for the community in the midst of an economic crisis. By fostering MSMEs, it is believed that economic recovery can be achieved. Basically, MSMEs are mostly informal in nature and therefore tend to be easier for new entrepreneurs to enter. Accounting information has a very important influence on achieving business success, including for small businesses. Accounting information in the form of financial statements can be the basis for MSMEs to make decisions in managing small businesses, including market development decisions, price development, and others. Micro, Small and Medium Enterprises (MSMEs) are synonymous with the lack of awareness to run bookkeeping well in the business world. So that the bookkeeping and filing processes have not been carried out properly and result in a lack of accountability for activities every period. The purpose of this service is to provide training and improvement of bookkeeping and filing at the Idol Bread Business in the city of Bukittinggi. The expected outcome of this dedication is the existence of a bookkeeping process and the improvement of good filing for the sake of business continuity in the future.
\end{abstract}

Keywords: Bookkeeping, Archiving

\begin{abstract}
Abstrak
Usaha Mikro, Kecil, dan menengah (UMKM) memiliki peranan bagi masyarakat di tengah krisis ekonomi. Dengan memupuk UMKM diyakini akan dapat dicapai pemulihan ekonomi. UMKM sendiri pada dasarnya sebagian besar bersifat informal dan karena itu cenderung lebih mudah untuk dimasuki oleh pelaku-pelaku usaha yang baru. Informasi akuntansi mempunyai pengaruh yang sangat penting bagi pencapaian keberhasilan usaha, termasuk untuk usaha kecil. Informasi akuntansi yang berupa laporan keuangan dapat menjadi modal dasar bagi UMKM untuk pengambilan keputusan-keputusan dalam pengelolaan usaha kecil, antara lain keputusan pengembangan pasar, pengembangan harga, dan lain-lain. Pelaku usaha Mikro, Kecil, dan Menengah (UMKM) identik dengan masih kurangnya kesadaran untuk menjalankan pembukuan dengan baik dalam dunia bisnis. Sehingga proses pembukuan dan pengarsipan belum terlaksana dengan baik dan berakibat kepada kurangnya pertanggungjawaban aktivitas setiap periodenya. Tujuan pengabdian ini adalah memberikan pelatihan dan pembenahan pembukuan dan pengarsipan pada Usaha Roti Idola di kota
\end{abstract}


Bukittinggi. Hasil yang diharapkan dari pengabdian ini adalah adanya proses pembukuan dan terbenahinya pengarsipan yang baik demi keberlangsungan usaha dimasa yang akan datang.

Kata Kunci: Pembukuan, Pengarsipan

\section{Pendahuluan}

Usaha Mikro, Kecil, dan menengah (UMKM) memiliki peranan bagi masyarakat di tengah krisis ekonomi. Dengan memupuk UMKM diyakini akan dapat dicapai pemulihan ekonomi. UMKM sendiri pada dasarnya sebagian besar bersifat informal dan karena itu cenderung lebih mudah untuk dimasuki oleh pelaku-pelaku usaha yang baru. Informasi akuntansi mempunyai pengaruh yang sangat penting bagi pencapaian keberhasilan usaha, termasuk untuk usaha kecil. Informasi akuntansi yang berupa laporan keuangan dapat menjadi modal dasar bagi UMKM untuk pengambilan keputusan-keputusan dalam pengelolaan usaha kecil, antara lain keputusan pengembangan pasar, pengembangan harga, dan lain-lain.

Dalam hubungannya dengan pemerintah dan kreditur (bank), penyediaan informasi juga diperlukan. Kewajiban penyelenggaraan pencatatan akuntansi yang baik bagi usaha kecil sebenarnya telah tersirat dalam Undang-Undang Usaha Kecil No. 9 Tahun 1995. Tapi kenyataannya, kebanyakan pengusaha kecil di Indonesia tidak menyelenggarakan dan menggunakan informasi akuntansi dalam pengelolaan usahanya.

Kesadaran akan akan pentingnya pembukuan justru sering timbul ketika mereka harus berhadapan dengan institusi atau pihak lain yang mensyaratkan adanya laporan keuangan atau istilah lainnya dalam akuntansi, untuk kegiatan tertentu. Misalnya untuk kepentingan meminjam modal ke bank. Salah seorang manajer klinik usaha kecildan keperasi Ikatan Akuntan Indonesia (IAI) menyatakan bahwa para pengusaha kecil tidak memiliki pengetahuan akuntansi, dan banyak diantara mereka yang belum memahami pentingnya pencatatan dan pembukuan bagi kelangsungan usaha. Sistem keuangan yang belum dilakukan dengan baik, mengakibatkan tercampurnya harta pribadi dengan harta perusahaan, sehingga pelaku usaha tidak dapat melakukan monitoring terhadap arus keuangan usaha.

Pengusaha kecil memandang bahwa proses pembukuan keuangan tidak terlalu penting untuk diterapkan. Dalam menjalankan aktivitas usaha seringkali orang merasa kesulitan dalam melakukan pencatatan terhadap apa yang terjadi di perusahaan. Kesulitan itu menyangkut aktivitas dan penilaian atas hasil yang dicapai oleh setiap usaha. Apalagi kalau harus dilakukan pengukuran dan penilaian atas aktivitas yang terjadi dalam kegiatan usaha.

Untuk mengembangkan usaha dapat dilakukan dengan cara pengukuran atau penilaian dari setiap aktivitas usaha. Oleh sebab itu pengusaha perlu menciptakan sebuah system pencatatan yang baik dari setiap aktivitas usaha tersebut. Dengan system pencatatan yang baik nantinya akan dihasilkan pelaporan hasil usaha dan kondisi perusahaan yang benar. Hal ini bias dilakukan jika unit usaha melakukan system akuntansi yang disesuaikan dengan jenis usahanya. Jika perusahaan belum mampu untuk menciptakan system akuntansi yang baik, minimal UMKM melakukan system pembukuan yang baik.

Selain dari lemahnya system pembukuan pada UMKM, proses pengarsipan dokumen pun ikut andil dalam keberlangsungan usaha dimasa yang akan datang. Setiap dokumen 
yang dibutuhkan oleh perusahaan kecil harus dilakukan pengarsipan yang memadai untuk mempertangungjawabkan hal-hal yang diperlukan dimasa yang akan datang. Karena keterbatasan sumber daya yang dimiliki serta keterbatasan anggaran untuk melaksanakan pelatihan pembukuan dan pengarsipan, oleh karena itu perlu diberikan pelatihan mengenai pembukuan dan pengarsipan untuk usaha kecil ini. Adapun usaha kecil yang dipilih adalah usaha roti Idola di kota Bukittinggi. Kegiatan ini dilakukan pada usaha roti Idola di kota Bukittinggi karena roti ini sudah mulai berkembang dan membutuhkan adanya system pembukuan serta pengarsipan yang memadai.

Usaha roti Idola ini berdiri pada tahun 2000 yang berlokasi di Jangkak. Namun pada tahun 2010 usaha roti ini memutuskan untuk pindah dikarenakan usaha roti Idola yang semakin berkembang. Saat ini alamat usaha roti Idola bertempat di Gadut, Tilatang Kamang Bukittinggi. Usaha roti Idola ini memiliki 10 orang pekerja bagian produksi roti dan 2 orang bagian pencatatan. Omset per bulan usaha roti Idola ini mencapai 10.000 .000 sampai 12.000.000 per bulan.

Pada saat ini usaha roti Idola telah mengalami perkembangan yang sangat pesat baik dari segi kualitas maupun kuantitas sesuai dengan tuntutan jaman. Usaha roti Idola selalu berusaha untuk meningkatkan penjualan per bulannya. Salah satu usaha untuk memperluas usahanya dilakukan penyebarluasan informasi dengan menyelenggarakan penggenalan roti melalui media elektronik.

Kondisi saat ini, di usaha roti Idola masih menggunakan pembukuan keuangan secara manual dan belum sesuai dengan standar yang keuangan berlaku. Selain itu pengarsipan dokumen tidak pernah dilakukan. Pembukuan keuangan dicatat pada buku yang berisikan uang masuk dan uang keluar serta pencatatan pesanan pelangganpun dicatat pada buku yang sama, selain itu usaha roti Idola belum melakukan pelaporan keuangan secara periodik guna melihat aktivitas yang dilakukan. Sementara untuk dapat meningkatkan perluasan usaha roti harus didanai dari pihak ketiga seperti Bank, sehingga dengan adanya system pembukuan beserta pengarsipan sesuai dengan standar keuangan yang berlaku dan dapat dipertanggungjawabkan kepada pemilik usaha dapat meningkatkan kualitas pada usaha roti idola tesebut.

Dokumentasi Usaha Roti Idola Bukittinggi

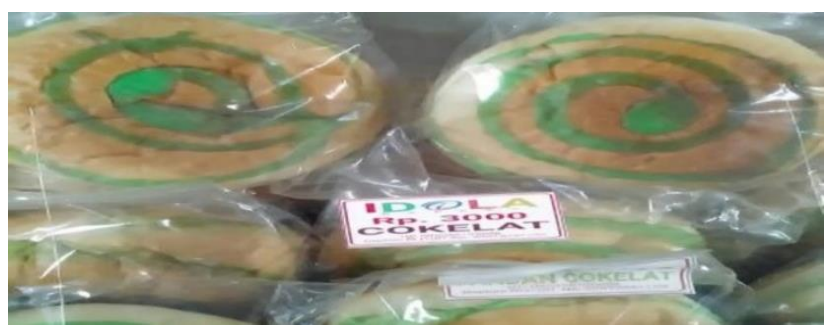

Gambar 1. Produk Roti Idola Bukittinggi 

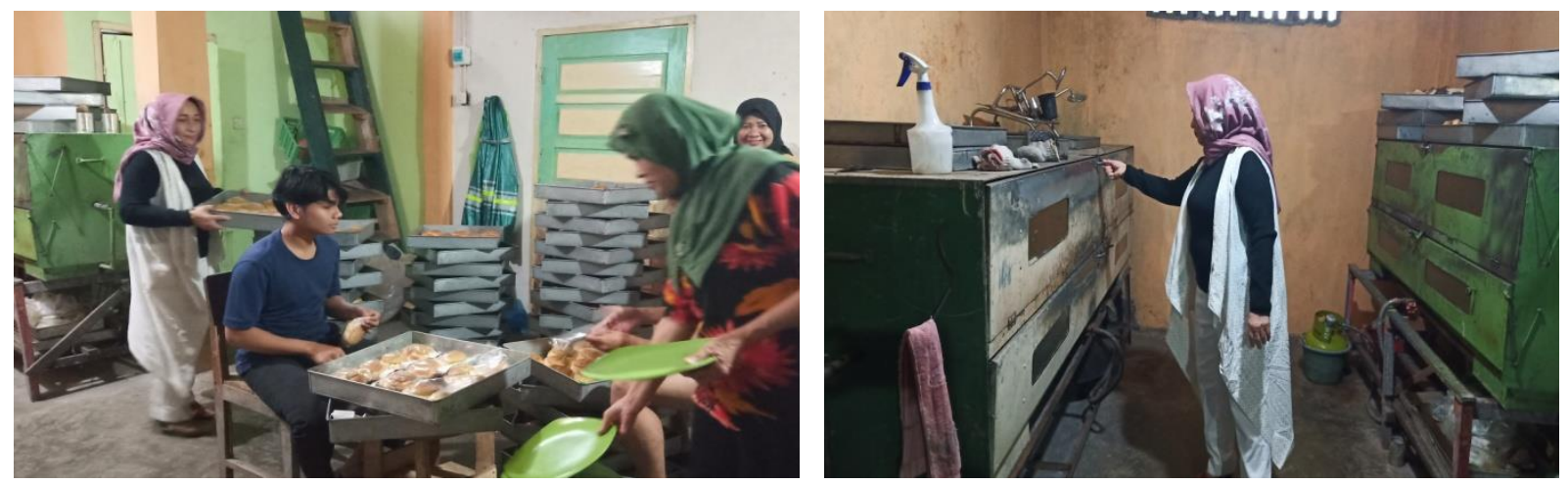

Gambar 2. Kondisi Pabrik Roti Idola Bukittinggi

\section{Permasalahan Mitra}

Sejauh ini pembukuan dan proses pengarsipan yang dilakukan pada mitra yang ditunjuk belum memadai karena adanya keterbatasan sumber daya dan anggaran untuk mengikuti pelatihan pembenahan pembukuan dan pengarsipan yang baik. Sementara sejauh ini usaha roti Idola masih mengalami kesulitan dalam hal mengatur pembukuan dan pengarsipan yang tertata dengan baik. Menanggapi permasalah tersebut, tim penulis ingin memberi pelatihan dan pembenahan pembukuan beserta pengarsipan yang bertujuan untuk meningkatkan keterampilan dan pengetahuan mengenai system pembukuan usaha agar tidak tercampur antara keuangan keluarga dengan keuangan usaha, serta dengan melakukan pembukuan keuangan ini, pelaku usaha dapat mengetahui perkembangan usahanya.

Masalah yang menjadi prioritas utama untuk diatasi pada kegiatan ini adalah:

1. Pelatihan

Pelatihan pembukuan dan pengarsipan sesuai dengan standar keuangan yang berlaku dan dapat dipertanggungjawabkan. Karena bagian keuangan pada usaha roti Idola belum menerapkan system pembukuan secara baik. Selain itu lemahnya proses pengarsipan juga menjadi kendala dalam mitra ini. Proses pengarsipan dokumen belum dilakukan secara memadai.

2. Pembenahan

Pembenahan system pembukuan dan prosedur pengarsipan sesuai standar yang berlaku. Pembenahan dilakukan dengan tujuan meningkatkan pelaporan keuangan yang dapat dipercaya dan dipertanggungjawabkan dengan didukung pengarsipan yang tertata dengan baik.

\section{Solusi yang Ditawarkan}

Solusi yang ditawarkan untuk menyelesaikan permasalahan yang dihadapi mitra adalah :

1. Memberikan pelatihan pembukuan untuk usaha kecil.

2. Memberikan pembenahan pembukuan dan pengarsipan untuk usaha kecil.

\section{Target dan Luaran}

1. Target pada kegiatan ini adalah memberikan pelatihan dan pembenahan pembukuan dan admistrasi secara memadai dan berdasarkan standar yang berlaku. 
2. Luaran yang dihasilkan adalah modul pelatihan dan pembenahan pembukuan dan administrasi yang bisa digunakan oleh usaha roti Idola dalam mengelola keuangan dan pembenahan administrasi. Disamping itu rencana capaian luaran yang ditargetkan dapat dilihat pada tabel dibawah ini :

Tabel 1. Rencana Target Capaian Luaran

\begin{tabular}{|c|c|c|}
\hline No & Jenis Luaran & $\begin{array}{c}\text { Indikator } \\
\text { Capaian }\end{array}$ \\
\hline \multicolumn{3}{|c|}{ Luaran Wajib } \\
\hline 1 & $\begin{array}{l}\text { Publikasi Ilmiah pada Jurnal ber ISSN/Prosiding Jurnal } \\
\text { Nasional }^{11}\end{array}$ & Summitted \\
\hline 2 & Publikasi pada media masa cetak/online/repocitory PT6) & Proses Editing \\
\hline 3 & $\begin{array}{l}\text { Peningkatan daya saing (peningkatan kualitas, kuantitas, } \\
\text { serta nilai tambah barang, jasa, diversifikasi produk, atau } \\
\text { sumber daya lainnya) }{ }^{4)}\end{array}$ & Penerapan \\
\hline 4 & $\begin{array}{l}\text { Peningkatan penerapan iptek di masyarakat (mekanisme, } \\
\text { IT, dan manajemen) }\end{array}$ & Penerapan \\
\hline 5 & $\begin{array}{l}\text { Perbaikan tata nilai masyarakat (seni budaya, sosial, politik, } \\
\text { keamanan, ketentraman, pendidikan, kesehatan) }{ }^{2)}\end{array}$ & $\begin{array}{l}\text { Sudah } \\
\text { dilaksanakan }\end{array}$ \\
\hline \multicolumn{3}{|c|}{ Luaran Tambahan } \\
\hline 1 & Publikasi di jurnal internasional1) & Tidak Ada \\
\hline 2 & Jasa; rekayasa sosial, metode atau sistem, produk/barang5) & Tidak Ada \\
\hline 3 & Inovasi baru TTG5) & Tidak Ada \\
\hline 4 & $\begin{array}{l}\text { Hak kekayaan intelektual (Paten, Paten sederhana, Hak } \\
\text { Cipta, Merek } \\
\text { dagang, Rahasia dagang, Desain Produk Industri, } \\
\text { Perlindungan Varietas } \\
\text { Tanaman, Perlindungan Desain Topografi Sirkuit } \\
\text { Terpadu) } \\
\text { 3) }\end{array}$ & Tidak Ada \\
\hline 5 & Buku ber ISBN6) & Tidak Ada \\
\hline 6 & Video & \\
\hline
\end{tabular}

\section{Metode Pelaksanaan}

Metode pelaksanaan kegiatan yang dilakukan dalam pengabdian ini terdiri dari Pelatihan dan Pembenahan serta Evaluasi dari kegiatan yang ditawarkan untuk mengatasi permasalahan mitra untuk peningkatan keberlangsungan usaha. Uraian justifikasi pengusul bersama mitra dalam menentukan persoalan prioritas yang disepakati untuk diselesaikan selama pelaksanaan program PKM, yaitu:

Masalah 1: Tidak melakukan pencatatan pembukuan usaha roti Idola Bukittinggi Untuk mengatasi masalah 1, maka dilakukanlah:

Pelatihan dan bimbingan teknik mengenai pembukuan keuangan yang baik sesuai dengan kebutuhan pengguna dan berdasarkan standar keuangan yang berlaku. Pelatihan ini dirancang secara khusus agar mudah dipahami oleh pengguna. Pemberian ilmu terkait dengan pembukuan serta diberikan simulasi terkait dengan pembukuan yang dibutuhkan 
oleh usaha roti Idola Bukittinggi. Tujuannya adalah agar pemilik dapat menerapkan pembukuan secara layak dan memadai sehingga proses pembukuan keuangan berjalan dengan baik dan dapat dipertanggungjawabkan.

Masalah 2: Belum adanya sistem administratif yang baik pada usaha roti Idola Bukittinggi

\section{Untuk mengatasi masalah 2, maka dilakukanlah:}

Pembenahan administrasi pada mitra dengan cara memberikan pelatihan sesuai dengan standar yang berlaku dan memadai. Selain itu untuk mengatasi masalah ini dilakukan juga simulasi sederhana bagaimana cara mengarsipkan dokumen yang baik sehingga pada saat penelusuran dokumen dapat dilakukan dengan mudah dan dapat dipertanggungjawabkan dengan baik.

\section{Prosedur Kerja}

Pada pengabdian kepada masyarakat ini dilakukan prosedur kerja sebagai berikut:

1. Kegiatan

Untuk kegiatan pelatihan dan pembenahan, jadwal pelatihan ditentukan dengan melakukan konfirmasi waktu terlebih dahulu kepada mitra. Sebelum pelatihan tim pelaksana akan menyiapkan modul agar para peserta pelatihan dapat cepat memahami materi.

2. Pendampingan/Asistensi

Kegiatan ini bertujuan untuk membantu pemilik usaha roti Idola Bukittinggi dalam memahami dan menjalankan pembukuan dan melakukan administrasi yang memadai. Dalam kegiatan ini tim pelaksana akan mendampingi pemilik mulai dari identifikasi dan penggelompokan dokumen sampai pengarsipan.

3. Evaluasi kegiatan

Evaluasi dilakukan secara langsung pada saat simulasi selama kegiatan berlangsung. Tujuan evaluasi ini adalah untuk perbaikan pelaksanaan berikutnya, maka akan didiskusikan dengan mitra untuk mencarikan solusi dan perbaikannya.

\section{Partisipasi Mitra}

Mitra dalam hal ini adalah pemilik usaha roti Idola Bukittinggi. Parsipasi mitra dalam kegiatan ini adalah:

1. Menyediakan tempat untuk kegiatan pelatihan dan pembenahan.

2. Memberi motivasi, pengawasan dan pembinaan selama kegiatan pengabdian kepada masyarakat kepada peserta yang ditunjuk.

\section{Evaluasi Program dan Keberlanjutan Program}

Evaluasi dilakukan secara langsung pada saat simulasi selama kegiatan berlangsung. Tujuan evaluasi ini adalah untuk perbaikan pelaksanaan berikutnya dan seandainya ada hambatan, maka akan didiskusikan dengan mitra untuk mencarikan solusi dan perbaikannya. Diharapkan ke depan akan terjalin kerjasama antara mitra dengan Politeknik Negeri Padang. Seiring dengan tujuan yang sama antara mitra dengan PNP yaitu sama-sama mencerdaskan anak bangsa dan mempunyai akhlak yang mulia. 


\section{Analisis Kebutuhan Mitra}

Kebutuhan mitra adalah sebagai berikut:

1. Membutuhkan pengetahuan dan pemahaman mengenai pembukuan keuangan dan administrasi yang memadai.

2. Memerlukan keterampilan dalam hal pengelolaan keuangan dengan baik.

3. Membutuhkan keahlian terkait dengan pengarsipan dokumen.

Hasil

Adapun hasil yang telah diperoleh dari kegiatan ini adalah:

1. Kemahiran dalam pengelolaan atau pembukuan keuangan pada usaha roti Idola Bukittinggi.

2. Keterampilan yang memadai dalam hal administrasi khususnya pengarsipan dokumen pada usaha roti Idola Bukittinggi.

\section{Ucapan Terima Kasih}

1. Politeknik Negeri Padang yang telah memberikan kesempatan dan bantuan dalam menyelesaikan kegiatan ini.

2. Bapak Surfa Yondri, ST.,S.ST.,M.Kom selaku Direktur Politeknik Negeri Padang.

3. Bapak Dr. Yuhefizar, S.Kom., M.Kom selaku Kepala P3M Politeknik Negeri Padang.

4. Ibu Dr. Amy Fontanella, SE., M.Si.,Ak selaku Ketua Jurusan Akuntansi Politeknik Negeri Padang.

5. Rekan-rekan Jurusan Akuntansi Politeknik Negeri Padang.

\section{Referensi}

[1] Bastian, Indra. 2001. Akuntansi untuk UMKM. Erlangga. Jakarta

[2] Brigham. 2014. Dasar-Dasar Manajemen Keuangan. Salemba Empat. Jakarta

[3] Sujarweni, Wiratna. 2014. Manajemen Keuangan dan Teori. Pustaka Baru. Jakarta

[4] Patongkko. 2017. Pedoman Administrasi. Erlangga. Jakarta 